\title{
Innovations
}

\section{The importance of communication that keeps at its core emotional states: Evidence from the Middle East}

\author{
Medical Humanities in the Middle East Conference \\ November 17-18, 2018 \\ Doha, Qatar
}

\section{Authors}

Angie Cucchi ${ }^{*}$

\section{Abstract}

Evolution and changes in the modern day approach to medical care, and the impact of the Internet as an external source of patient information and tool for decision-making, have precipitated a significant shift in the doctor-patient relationship over the past 30 years. ${ }^{1}$ This has translated into a move from a paternalistic, physician-dominated approach, reliant on "top-down" presentation of information, to a more patient-centred one, concerned with mutual participation and service users' satisfaction. ${ }^{1,2}$ In the $21^{\text {st }}$ century, medical and clinical decisions are determined by a shared decision-making process between the doctor and the patient. ' Hence, the implications of the shift in the doctor-patient relationship have been felt not only in the application of technical knowledge, but primarily, on how information is communicated to patients. The $21^{\text {st }}$ century doctors face the challenge of having to present information in a way that maximises understanding and encourages collaboration. This has consequently precipitated a sudden and novel interest in doctor-patient communication skills in the literature.

Research suggests that physicians with poor communication skills are judged by patients to be inefficient doctors ${ }^{3}$ and that they are more liable to engage in malpractice. ${ }^{4,5}$ Hence, the assessment and teaching of communication skills has become a crucial element of medical schools' learning process and medical educators are strongly encouraged to help students to develop patientcentered communication throughout medical school and via ongoing postgraduate workshops. ${ }^{6,7}$
'St. Mary's University, Twickenham, UK

*Email: angiecuc@hotmail.com

Angie Cucchi iD https://orcid.org/0000-0001-7724-2399

\section{Cite this article as:}

Cucchi A. The importance of communication that keeps at its core emotional states: Evidence from the Middle East. In: Weber AS, Verjee MA, editors. Proceedings of the lst International Conference on Medical Humanities in the Middle East [Internet]; 2018 Nov 17-18: Doha, Qatar: Innovations in Global Health Professions Education; 2019 March. p. 30-32. (Innovations in Global Health Professions Education; vol. 2019, spec. no.: 1). https://dx.doi.org/10.20421/ighpe2019.01.10

This is an open access article distributed under the terms of the Creative Commons Attribution license CC BY 4.0, which permits unrestricted use, distribution and reproduction in any medium, provided the original work is properly cited. 
Some researchers have argued that communication skills are not well taught as part of medical schools' curricula in the Middle East (ME), 7,8 leaving physicians at different levels of training lacking crucial communication skills. ${ }^{9}$ Despite these claims and despite a growing interest in this topic, ${ }^{7,8,10}$ very little has been published on patients' satisfaction with physicians' communication skills in the $\mathrm{ME}$, prompting some researchers to call for large scale studies. ${ }^{10}$

Effective communication is a complex skill that requires a combination of technical and social/ interpersonal competence. ${ }^{4}$ The former relates to the more technical aspect of communication such as the explanation of procedures, side effects and diagnoses. The latter, instead, taps into the more social and interpersonal aspects of communication connected with non-verbal components such as empathy and respect, and connected with emotions such as compassion and kindness. Interestingly, when patients' complaints were analysed qualitatively, Kee, Khoo, Lim \& Koh"1 discovered that perceived poor attitude, including perceived lack of respect and lack of empathy, was the most common and most reported complaint. Similar results were replicated in Saudi Arabia when a factor analysis of the Communication Assessment Tool-Team (CAT-T) questionnaire, used to assess doctors' communication skills, identified 4 main factors, including empathy and sensitivity, greeting and introductions, language and listening, as well as information sharing. ${ }^{9}$ Worryingly, the data of Al Nasser et al. ${ }^{9}$ reported a discrepancy between the physicians' insights of their communication skills and carers' perceptions, indicating the need for further studies and targeted training for professionals.

Answering calls from the region to assess clinicians' communication skills from a patient perspective, Al Hemiary et al. ${ }^{12}$ investigated such skills in Iraqi physicians. Whilst other studies in the ME had previously addressed this issue, ${ }^{7-10} \mathrm{Al}$ Hemiary et al. ${ }^{12}$ is the first to differentiate between interpersonal and content-based communication, hence shedding more light on the complexity of verbal and non-verbal exchanges in the doctorpatient relationship. Findings highlight higher satisfaction rates for the former, suggesting that Iraqi physicians might be naturally inclined to pay attention to interpersonal dynamics and communication that keeps emotional states at its core. In addition, the results suggest that in Iraq, patients' satisfaction rates of the clinicians' communication skills correlated with the physician's rank, length of service and duration of care. ${ }^{12}$ These findings indirectly support the importance of the therapeutic alliance for patients' satisfaction and the utmost need to incorporate communication skills training as part of medical school's curricula in the ME, with a particular focus on the technical aspect of communication in Iraq.

Conflicts of interest: None.

Funding sources: Attendance to the Medical Humanities in the Middle East Conference was funded by the British Psychological Society Early Career Conference Bursary Scheme.

\section{References}

1. Kaba R, Sooriakumaran P. The evolution of the doctor-patient relationship. Int J Surg. 2007 Feb;5(1):57-65. doi: 10.1016/j. ijsu.2006.01.005

2. Abadel FT, Hattab AS. Patients' assessment of professionalism and communication skills of medical graduates. BMC Med Educ. 2014 Feb 11;14:28. doi:10.1186/1472-6920-14-28

3. Stewart M, Brown JB, Boon H, Galajda J, Meredith L, Sangster M. Evidence on patientdoctor communication. Cancer Prev Control. 1999 Feb;3(1):25-30.

4. Hickson GB, Clayton EW, Entman SS, Miller CS, Githens PB, Whetten-Goldstein K, et al. Obstetricians' prior malpractice experience and patients' satisfaction with care. Jama. 1994 Nov 23-30;272(20):1583-7.

5. Levinson W, Roter DL, Mullooly JP, Dull VT, Frankel RM. Physician-patient communication. The relationship with malpractice claims among primary care physicians and surgeons. Jama. 1997 Feb 19;277(7):553-9.

6. Berman AC, Chutka DS. Assessing effective physician-patient communication skills: "Are 
you listening to me, doc?". Korean J Med Educ. 2016 Jun;28(2):243-9. doi:10.3946/kjme.2016.21

7. Al-Shehri MY. Communication skills courses: a plea for inclusion in the medical curriculum. Saudi J Health Sci [Internet]. 2012 [cited 2018 Nov 18]; 1(1):2-4. Available from: http://www. saudijhealthsci.org/text.asp?2012/1/1/2/94976

8. Cegala DJ, Lenzmeier Broz S. Physician communication skills training: a review of theoretical backgrounds, objectives and skills. Med Educ. 2002 Nov;36(11):1004-16.

9. Alnasser $Y S$, Bin Nafisah HM, Almubarak ZA, Aleisa LA, El Sarrag Al, Babiker AM. Communication skills between physicians' insights and parents' perceptions in a teaching hospital in KSA. J Taibah Univ Med Sci [Internet]. 2017 [cited 2018 Nov 18]; 12(1):3440. Available from: http://www.sciencedirect. com/science/article/pii/S1658361216300981. doi:10.1016/j.jtumed.2016.09.002

10. Zolaly MA. Satisfaction of parents of paediatric patients with physicians' communication skills in Almadinah Almunawwarah, Kingdom of Saudi Arabia. J Taibah Univ Med Sci [Internet]. 2012 [cited 2018 Nov 18]; 7(1):29-34. Available from: http://www.sciencedirect.com/science/ article/pii/S165836121200008X. doi:10.1016/j. jtumed.2012.07.007

11. Kee JWY, Khoo HS, Lim I, Koh MYH. Communication skills in patient-doctor interactions: learning from patient complaints. Health Prof Educ [Internet]. 2018 [cited 2018 Nov 18]; 4(2):97-106. Available from: http://www.sciencedirect.com/science/ article/pii/S2452301116301225. doi:10.1016/j. hpe.2017.03.006
12. Al-Hemiary N, Cucchi A, Al Nuaimi A, Al-Saffar H, Al-Ani K, Ibrahim Q, et al. Context versus content: assessment of communication skills in Iraqi physicians. A cross-sectional study. 2018. Unpublished.

\section{About the author}

Dr. Cucchi is a Chartered Psychologist with research and practice interests in the field of Eating Disorders, Personality Disorders and cross-cultural issues. She has won the British Psychological Society Research Prize and trainee prize 2015. She currently works in a Personality Disorder Unit whilst holding an academic position at St. Mary's University, Twickenham. 